\title{
Fluoroquinolone antibacterial eye drops: effects on normal human corneal epithelium, stroma, and endothelium
}

This article was published in the following Dove Press journal:

Clinical Ophthalmology

6 October 2010

Number of times this article has been viewed

\section{Ryou Watanabe \\ Toru Nakazawa \\ Shunji Yokokura \\ Akira Kubota \\ Hisayo Kubota \\ Kohji Nishida}

Department of Ophthalmology, Tohoku University Graduate School of Medicine, Aoba-ku, Sendai, Japan
Correspondence: Ryou Watanabe Department of Ophthalmology, Tohoku University Graduate School of Medicine, I-I Seiryo-machi, Aoba-ku, Sendai, Miyagi 980-8574, Japan

Tel +8I $227 \mid 77294$

Fax +8I 227177298

Email ryo-w@oph.med.tohoku.ac.jp
Background: In vitro studies have suggested the corneal cytotoxicity of third-generation fluoroquinolone levofloxacin (LVFX) and fourth-generation fluoroquinolone moxifloxacin hydrochloride (MFLX) among fluoroquinolone antibacterial eye drops. This study investigated the effects of these two eye drops on the human cornea in vivo.

Methods: We evaluated 30 healthy adults (19 men and 11 women, $38.3 \pm 6.3$ years old). Each subject received an LVFX ophthalmic solution $0.5 \%$ in one eye and an MFLX ophthalmic solution $0.5 \%$ in the other eye three times daily for 7 days. Functional and morphological corneal changes before and after instillation were evaluated through ophthalmic examinations including breakup time of tear film (BUT) as measured by fluorescein staining and DR-1, Schirmer I test, Heidelberg Retina Tomograph II Rostock Cornea Module (HRTII-RCM), specular microscope, and Pentacum examination.

Results: Both the LVFX and MFLX groups had no significant change in each examination before and after instillation. There was also no statistically significant difference in measurements after the 7-day instillation between the groups.

Conclusion: Our study results suggest that as with LVFX, MFLX used in a normal clinical setting is unlikely to cause any obvious adverse effects on human normal cornea.

Keywords: cornea, fluoroquinolones, ocular surface, toxicity

\section{Introduction}

Fluoroquinolone antibacterial eye drops are a broad spectrum antibacterial that effectively inhibit two enzymes, bacterial topoisomerase IV and topoisomerase II (DNA gyrase). They are widely used for ocular infections and perioperative prophylaxis in ophthalmic surgery because of these advantages.

Fluoroquinolones are relatively safe, although they have shown inhibitory activity against mammalian topoisomerase II, which is related to bacterial DNA gyrase. ${ }^{1}$ It is therefore also possible that fluoroquinolone antibacterial eye drops have some influence on corneal cells. In vitro studies of fluoroquinolone using human corneal keratocyte cultures suggest that levofloxacin (LVFX) and moxifloxacin (MFLX) may be cytotoxic. ${ }^{2}$ However, the effects of these drugs in vivo remain to be determined.

In the present study, using a moxifloxacin ophthalmic solution $0.5 \%$ (MFLX) (Vegamox; Alcon Japan, Tokyo, Japan), a fourth-generation fluoroquinolone with excellent aqueous penetration ${ }^{3,4}$ and a levofloxacin ophthalmic solution $0.5 \%$ (LVFX) (Cravit, Santen Pharmaceutical, Osaka, Japan), a third-generation fluoroquinolone used widely in Japan, we investigated the effects of these fluoroquinolone antibacterial eye drops on normal human cornea in terms of the break-up time of tear film (BUT) and 
the morphological appearance of the corneal epithelium, stroma, and endothelium.

\section{Methods}

The protocol for this research project has been approved by the Ethics Committee of Tohoku University Graduate School of Medicine and it conforms to the provisions of the Declaration of Helsinki in 1995. This study gave informed consent and patient anonymity was preserved. We recruited 40 healthy adult volunteers from the public at the Department of Ophthalmology, Tohoku University Graduate School of Medicine. Among them, 30 volunteers were judged eligible for participation through the screening test and, after providing informed consent, they were randomly assigned to two groups. Subjects in one group received MFLX in their left eye or LVFX in their right eye and those in the other group received MFLX in their right eye or LVFX in their left eye. The study was conducted in a single blind fashion where only the investigator was masked to the allocated study eye drops.

Subjects received one drop of MFLX or LVFX in either eye three times a day for 7 days. Before and after instillation of the study eye drops, the effects of each study drug on the corneal epithelium, stroma, and endothelium were evaluated through the method described later in this paper.

The exclusion criteria for this study included a history of hypersensitivity to fluoroquinolones, corneal epithelial defects (including superficial punctate keratopathy (SPK)), conjunctivitis, a history of herpetic keratitis, abnormal lacrimation (a Schirmer I test measurement of $5 \mathrm{~mm}$ or less or a BUT measurement of 5 seconds or less), use of any antibacterial eye drops within 1 week of study entry, use of eye drops other than the study eye drops, use of contact lenses within 2 weeks of study entry, intraocular pressure of $21 \mathrm{mmHg}$ or more, inability of the subject to provide written informed consent, and any other reason judged ineligible for participation in the study by the investigator.

\section{Study eye drops}

The eye drops used in the present study were MFLX and LVFX, both of which did not contain benzalkonium chloride and are commercially available in Japan.

\section{Evaluations}

Two weeks before study entry and on the last day of study (after 7 days of instillation), subjects underwent a general ocular examination including slit-lamp microscopy, evaluation of the influence on the corneal epithelium by fluorescein staining, ${ }^{5}$ BUT measurement with fluorescein staining and with a DR-1 (Tear film lipid layer interferometry system, Kowa, Nagoya, Japan), and a Schirmer I test. In addition to these tests, corneal function and morphological changes were observed using a specular microscope (Topcon SP-3000P, Topcon Ltd, Tokyo, Japan), Pentacam (Oculus, Wetzlar, Germany), and Heidelberg Retina Tomograph II Rostock Cornea Module (HRTIIRCM) (Heidelberg Engineering, Dossenheim, Germany). On the last day of the study, treatment compliance and the development of any adverse events were confirmed. In addition, subjects were asked to complete a questionnaire to assess their satisfaction with the study eye drops (irritating sensation and drop comfort upon instillation) using a visual analog scale (VAS) (0 to $100 \mathrm{~mm}$ ). Table 1 summarizes the observation items and details of each item.

The DR-1 is a system designed to observe interference colors generated by a specular light from the tear film lipid layer and classify the status of dry eye into five grades for evaluation. Normal eyes exhibit a gray interference color that is distributed uniformly, whereas dry eyes frequently show two or more interference colors (Grade 3, 4, and 5). In severe dry eyes, tear production with blinking is inadequate and the corneal surface is partially exposed (Grade 5). ${ }^{6}$ HRTII-RCM allows noninvasive in vivo observation of the corneal microstructure including epithelium, stroma, and endothelium. ${ }^{7}$ The range of the captured HRTII-RCM picture was $400 \times 400 \mu \mathrm{m}$, and the resolution power of the image was $384 \times 384$ pixels. The Pentacam is a rotating single Scheimpflug camera system. It computes anterior and posterior curvatures and provides complete corneal pachymetry of the entire cornea.

\section{Statistical analysis}

Subject data were entered and analyzed using the following software: Microsoft Excel 2003 (Microsoft Corporation, Redmond, WA) and JMP Version 6 (SAS Institute Japan Ltd, Tokyo, Japan).

Comparison of the two study eye drops was performed by the paired $t$-test. Measurements are represented in mean \pm standard deviation. The grading of the tear film lipid layer was made with the Mann-Whitney $U$-test. Comparison of the patients with epithelial defects before and after treatment was performed using Fisher's exact test.

\section{Results}

The 30 subjects consisted of 19 men and 11 women (mean age \pm standard deviation: $38.3 \pm 6.3$ years). Throughout the 
Table I The observation items and details of each item

\begin{tabular}{|c|c|c|c|c|c|c|}
\hline \multirow[t]{2}{*}{ Observation item } & \multicolumn{2}{|c|}{$\begin{array}{l}\text { Timing of } \\
\text { observation }\end{array}$} & \multicolumn{3}{|c|}{$\begin{array}{l}\text { Observation } \\
\text { of cornea }\end{array}$} & \multirow[t]{2}{*}{ Endothelium } \\
\hline & 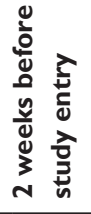 & 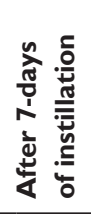 & 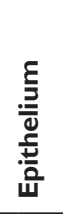 & 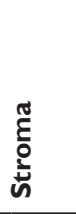 & 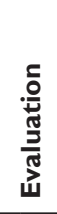 & \\
\hline Informed consent & $\circ$ & & & & & \\
\hline Subject background & $\circ$ & & & & & \\
\hline Concomitant drugs & $\circ$ & $\circ$ & & & & \\
\hline Visual acuity test & $\circ$ & $\circ$ & & & & \\
\hline Treatment compliance & & $\circ$ & & & & \\
\hline Slit-lamp microscopy & $\circ$ & $\circ$ & $\checkmark$ & & & Observation of the corneal epithelium \\
\hline $\begin{array}{l}\text { Anterior-segment pictures } \\
\text { (fluorescein staining) (BUT) }\end{array}$ & ० & ० & $\checkmark$ & & & Evaluation of the influence on the corneal epithelium \\
\hline Specular microscope & $\circ$ & $\circ$ & & & $\checkmark$ & $\begin{array}{l}\text { Observation of the corneal endothelium. Measurement of } \\
\text { endothelial cell density, and coefficient of variation (CV) }\end{array}$ \\
\hline DR-I (BUT) & $\circ$ & $\circ$ & $\checkmark$ & & & $\begin{array}{l}\text { Evaluation of influence on the corneal epithelium based on } \\
\text { tear film lipid layer grading }\end{array}$ \\
\hline Schirmer I test (BUT) & ० & ० & $\checkmark$ & & & Lacrimation function based on tear volume \\
\hline $\begin{array}{l}\text { Pentacarn (Corneal } \\
\text { thickness) }\end{array}$ & $\circ$ & $\circ$ & & $\checkmark$ & & $\begin{array}{l}\text { Measurement of corneal thickness (influence on the } \\
\text { corneal endothelium) }\end{array}$ \\
\hline HRT II-RCM & o & ० & & $\checkmark$ & & $\begin{array}{l}\text { Morphological observation of the corneal stroma } \\
\text { Evaluation of cell density }\end{array}$ \\
\hline Adverse events & $\circ$ & $\circ$ & & & & \\
\hline $\begin{array}{l}\text { Questionnaire to assess } \\
\text { satisfaction with use }\end{array}$ & & $\circ$ & & & & $\begin{array}{l}\text { Assessment of irritating sensation and drop comfort upon } \\
\text { instillation using a VAS }\end{array}$ \\
\hline
\end{tabular}

study, they had favorable treatment compliance and each subject instilled the assigned study eye drops reliably.

\section{Influence on the corneal epithelium BUT}

BUT scores measured by fluorescein staining before and after the 7 days of instillation were $13.8 \pm 5.8$ seconds and $11.9 \pm 6.5$ seconds, respectively, for eyes instilled with MFLX (MFLX group) and $13.6 \pm 5.4$ seconds and $10.4 \pm 6.0$ seconds, respectively, for eyes instilled with LVFX (LVFX group). No significant change was observed in either group before or after the 7 days of instillation, and no statistically significant difference between the groups was observed in measurements after the 7 days of instillation ( $P=0.4376, t$-test $)$.

BUT scores measured by DR-1 before and after the 7-day instillation were $29.0 \pm 12.4$ seconds and $22.8 \pm 13.6$ seconds, respectively, for the MFLX group and $29.4 \pm 14.2$ seconds and $22.3 \pm 14.3$ seconds, respectively, for the LVFX group. No significant change was observed in either group before or after the 7-days of instillation, and no statistically significant difference between groups was observed in measurements after the 7-days of instillation ( $P=0.8795, t$-test $)$.
Grades of the tear film lipid layer using the DR- 1 before and after the 7 days of instillation were $2.2 \pm 0.5$ and $2.8 \pm 0.6$, respectively, for the MFLX group and $2.1 \pm 0.6$ and $2.8 \pm 0.4$, respectively, for the LVFX group. No statistically significant difference between the groups was observed in grades after the 7-days of instillation ( $P=0.9709, U$-test). Changes in the grade were seen in $56.7 \%$ of subjects (17/30) in the MFLX group and in $66.7 \%$ of subjects (20/30) in the LVFX group, all changes were slight.

Schirmer I test scores before and after the 7 days of instillation were $20.9 \pm 9.3 \mathrm{~mm}$ and $18.4 \pm 11.2 \mathrm{~mm}$, respectively, for the MFLX group and $19.3 \pm 9.9 \mathrm{~mm}$ and $19.2 \pm 11.3 \mathrm{~mm}$, respectively, for the LVFX group. No significant change was observed in either group before or after the 7 days of instillation, and no statistically significant difference between the groups was observed in scores after the 7 days of instillation ( $P=0.3325, t$-test).

\section{Corneal epithelial defects according to area and density grading}

The severity of superficial punctate keratitis (SPK) can be classified into nine grades according to the area and density (AD) grading which is the combination of the area (A) and density (D) 


\begin{tabular}{|c|c|c|c|c|c|}
\hline Group & \multicolumn{2}{|c|}{$\begin{array}{c}\text { Before } \\
\text { instillation }\end{array}$} & $\begin{array}{l}\text { After } \\
7 \text { days }\end{array}$ & & $\begin{array}{l}P \text { - } \\
\text { ralue }\end{array}$ \\
\hline MFLX & \multicolumn{2}{|c|}{$0 / 30$} & $8 / 30$ & & \multirow{2}{*}{0.67} \\
\hline LVFX & \multicolumn{2}{|c|}{$0 / 30$} & $7 / 30$ & & \\
\hline \multicolumn{6}{|c|}{$A D$ grading of each eye } \\
\hline & \multicolumn{2}{|c|}{ LVFX } & \multicolumn{2}{|c|}{ MFLX } & \\
\hline & $\begin{array}{c}\text { Before } \\
\text { instillation }\end{array}$ & $\begin{array}{c}\text { After } 7 \\
\text { days }\end{array}$ & $\begin{array}{c}\text { Before } \\
\text { instillation }\end{array}$ & After 7 days & \\
\hline & AODO & A1D1 & AOD0 & A1D1 & \\
\hline & AODO & A1D1 & A0D0 & A1D1 & \\
\hline & AODO & A1D1 & AODO & A1D1 & \\
\hline & A0D0 & A1D1 & AODO & A1D1 & \\
\hline & AODO & A1D1 & A0D0 & A1D1 & \\
\hline & A0D0 & A1D1 & A0D0 & A1D1 & \\
\hline & A0D0 & A1D1 & A0D0 & A1D1 & \\
\hline & & & A0D0 & A1D1 & \\
\hline
\end{tabular}

Figure I Corneal epithelial defects according to AD grading. After 7 days of instillation, corneal epithelial defects were observed in eight eyes of the subjects receiving MFLX and seven eyes of the subjects receiving LVFX. AD grading of the 15 eyes was AIDI for I4 eyes and A2DI for the remaining eye. No statistically significant difference between the groups was observed in the incidence of epithelial defects $(P=0.675, t$-test).

of the lesion stained as dots by fluorescein staining (Figure 1). ${ }^{7}$ In this study, the severity of corneal epithelial defects was evaluated using AD grading. Before instillation, corneal epithelial defects were not observed in any subject of either group, however, after the 7 days of instillation, corneal epithelial defects were observed in eight eyes of the subjects receiving MFLX and seven eyes of the subjects receiving LVFX. Among these subjects, four had mild epithelial defects in both eyes. AD grading of the 15 eyes was A1D1 for 14 eyes and A2D1 for the remaining eye. There was a statistically significant difference between groups before and after the instillation of MFLX $(P=0.0046$, Fisher's exact test). In addition, there was a statistically significant difference between groups before and after the instillation of LVFX ( $P=0.0105$, Fisher's exact test). No statistically significant difference between the groups was observed in the incidence of epithelial defects $(P=0.675, t$-test $)$.

\section{Influence on the corneal stroma}

\section{Cell density of the corneal stroma}

Changes in cell density of the superficial, middle, and deep layers of the corneal stroma were observed.

Cell density of the superficial layer of the corneal stroma before and after the 7 days of instillation was $643 \pm 53 \mathrm{cell} / \mathrm{mm}^{2}$ and $633 \pm 42 \mathrm{cell} / \mathrm{mm}^{2}$, respectively, for the MFLX group and $625 \pm 42 \mathrm{cell} / \mathrm{mm}^{2}$ and $630 \pm 36 \mathrm{cell} / \mathrm{mm}^{2}$, respectively, for the LVFX group. No statistically significant difference between the groups was observed in measurements after the 7 days of instillation.

Cell density of the middle layer of the corneal stroma before and after the 7 days of instillation was $488 \pm 20 \mathrm{cell} / \mathrm{mm}^{2}$ and $487 \pm 22$ cell $/ \mathrm{mm}^{2}$, respectively, for the MFLX group and $481 \pm 26 \mathrm{cell} / \mathrm{mm}^{2}$ and $485 \pm 25 \mathrm{cell} / \mathrm{mm}^{2}$, respectively, for the LVFX group. No statistically significant difference 
between the groups was observed in measurements after the 7 days of instillation.

Cell density of the deep layer of the corneal stroma before and after the 7 days of instillation was $428 \pm 22 \mathrm{cell} / \mathrm{mm}^{2}$ and $421 \pm 21 \mathrm{cell} / \mathrm{mm}^{2}$, respectively, for the MFLX group and $423 \pm 27 \mathrm{cell} / \mathrm{mm}^{2}$ and $424 \pm 25 \mathrm{cell} / \mathrm{mm}^{2}$, respectively, for the LVFX group. No statistically significant difference between the groups was observed in measurements after the 7 days of instillation.

No significant change was observed in any layer before or after the 7 days of instillation, and no statistically significant difference between the groups was observed in measurements after the 7 days of instillation.

No Langerhans cells or inflammatory cells appeared in any of the layers.

\section{Influence on the endothelium}

\section{Endothelial cell density}

Endothelial cell density before and after the 7 days of instillation was $2817.9 \pm 250.2 \mathrm{cell} / \mathrm{mm}^{2}$ and $2778.0 \pm 221.5 \mathrm{cell} / \mathrm{mm}^{2}$, respectively, for the MFLX group and $2816.1 \pm 255.7 \mathrm{cell} / \mathrm{mm}^{2}$ and $2808.9 \pm 261.9 \mathrm{cell} / \mathrm{mm}^{2}$, respectively, for the LVFX group. No significant change was observed in either group before or after the 7 days of instillation, and no statistically significant difference between the groups was observed in measurements after the 7 days of instillation $(P=0.3195, t$-test $)$.

In addition, the coefficient of variation $(\mathrm{CV})$ before and after the 7 days of instillation was $29.9 \% \pm 5.3 \%$ and $30.3 \% \pm 5.1 \%$, respectively, for the MFLX group and $30.9 \% \pm 6.7 \%$ and $29.7 \% \pm 5.2 \%$, respectively, for the LVFX group. No significant change was observed in either group before or after the 7 days of instillation, and no statistically significant difference between the groups was observed in measurements after the 7 days of instillation $(P=0.2295, t$-test $)$.

\section{Measurement of corneal thickness}

Corneal thickness measured with Pentacam before and after the 7 days of instillation were $561.9 \pm 38.6 \mu \mathrm{m}$ and $561.8 \pm 39.2 \mu \mathrm{m}$, respectively, for the MFLX group and $558.4 \pm 37.6 \mu \mathrm{m}$ and $559.5 \pm 39.7 \mu \mathrm{m}$, respectively, for the LVFX group. No major change was observed in either group before or after the 7 days of instillation, and no statistically significant difference between the groups was observed in measurements after the 7 days of instillation $(P=0.6305, t$-test $)$.

\section{Safety}

No serious adverse events were reported in either group. No clinically important changes in general ocular findings were also noted.

\section{Satisfaction with the study eye drops}

All 30 subjects were asked to complete a questionnaire to assess their satisfaction with the study eye drops (irritating sensation and drop comfort upon instillation) using a VAS ( 0 to $100 \mathrm{~mm})$. The mean value ( $95 \%$ confidence interval) of "irritating sensation" was $23.0 \mathrm{~mm}$ (14.1-31.8 mm) for MFLX and $31.0 \mathrm{~mm}(22.4-39.6 \mathrm{~mm})$ for LVFX, showing a trend slightly favoring MFLX, however, no statistically significant difference was noted $(P=0.1658$, Wilcoxon ranksum test). The mean value (95\% confidence interval) of "drop comfort upon instillation" was $20.5 \mathrm{~mm}$ (12.9-28.1 mm) for MFLX and $25.7 \mathrm{~mm}$ (17.1-34.4 mm) for LVFX, also showing a trend slightly favoring MFLX, however, no statistically significant difference was noted $(P=0.4539$, Wilcoxon rank-sum test).

\section{Discussion}

Although LVFX is a third-generation fluoroquinolone with a relatively broad spectrum of antibacterial activity, it has the disadvantage of being less active against gram-positive cocci. The minimum inhibitory concentrations of fourth-generation fluoroquinolones, MFLX and gatifloxacin (GFLX), against staphylococci and streptococci are higher than those of LVFX, and these fluoroquinolones are characterized by their broader antibacterial spectrum. In particular, since MFLX is known to have an approximately two- to three-fold lower ocular penetration than other antibacterial eye drops, ${ }^{3,4}$ this drug is expected to provide excellent clinical benefits. The superior penetration of MFLX is considered to be due to its unique physicochemical structure that combines high lipophilicity for enhanced corneal penetration with high aqueous solubility at physiological $\mathrm{pH} .{ }^{3,4}$ However, it has not yet been clearly defined whether its excellent penetration could have some influence on the cornea.

The effect of fourth-generation fluoroquinolones, Zymar $^{\circledR}$ (gatifloxacin ophthalmic solution, Allergan, Inc, Irvine, CA) and VIGAMOX ${ }^{\circledR}$ (moxifloxacin ophthalmic solution; Alcon Laboratories, Inc, Fort Worth, TX), on the corneal epithelial cells and intercellular space was investigated in an in vivo study using rabbits, evaluating the effect on tight junctions using ZO-1 immune staining. It was reported that in rabbits treated with VIGAMOX ${ }^{\circledR}$, 
corneal epithelial cell integrity was maintained with no effect on tight junctions, whereas in rabbits treated with Zymar $^{\circledR}$, decreased corneal epithelial cells and breakdown of tight junctions were observed, suggesting that benzalkonium chloride, an additive in $Z y m a r^{\circledR}$, was responsible for this effect. ${ }^{8}$ In the present study to objectively evaluate the in vivo effect of the fluoroquinolone eye drops in normal human eyes, although some subjects experienced mild corneal epithelial defects according to the AD grading, no statistically significant difference was observed between the two eye drops, LVFX and MFLX. Moreover, no obvious adverse effects of either drug on the corneal epithelium, stroma, and endothelium were noted in other evaluations. Furthermore, there were no issues concerning safety or subjective satisfaction with use of the study eye drops.

In vitro studies using cell cultures of human corneal keratocyte reported based on the proportion of concentrationtime exposures in which fluoroquinolones were cytotoxic, ciprofloxacin was the most cytotoxic to human corneal keratocyte (96\%), followed by MFLX (67\%), ofloxacin $(62.5 \%)$, GFLX (58\%), and LVFX (42\%) concluding that fluoroquinolones may differ in their cytotoxic potential to human corneal keratocytes. ${ }^{2}$ However, this study revealed that there was no statistically significant difference between the groups before and after the 7 days of instillation. We also find that no Langerhans cells or inflammatory cells displayed in any of the stromal layers. These results suggest that both LVFX and MFLX affect no toxicity to the cornea. In addition, it is difficult to consider that MFLX has some influence on the corneal stroma under normal conditions. In the present study, we instilled the fluoroquinolone antibacterial eye drops into normal human eyes, and have concluded that these fluoroquinolone, used in a normal clinical setting, are less likely to cause such histological changes due to cytotoxicity. Therefore, the use of fluoroquinolone eye drops on the normal cornea for sterilization before intraocular surgery or prophylaxis against postoperative infection should not raise concerns about cytotoxicity in corneal cells.

Only healthy volunteers were included in this study. Thus, there are limitations in applying our findings to patients with dry eyes or abnormal epithelia. Furthermore, our results may have been different if the frequency of instillation had been increased (eg, instillations every hour for corneal ulcers). In severe cases with corneal abnormalities, the effects of antibiotics should be checked carefully. There may be limitations in comparing two antibiotics using some examinations with a high degree of variability in this study, such as BUT. However, there is no clear difference between two antibiotics in the series of our routine eye examinations here.

A randomized comparative study of MFLX $1 \%$ ophthalmic solution, in which the concentration is twice that of the product marketed in Japan, in patients with bacterial keratitis, the safety of MFLX was comparable to the comparators, OFLX $0.3 \%$ ophthalmic solution and tobramycin (1.33\%)/ cephazolin $(5 \%)$ ophthalmic solution, and the time to cure in non-exiting patients tended to be shorter for MFLX than for OFLX. ${ }^{9}$ Moreover, a study of MFLX $0.5 \%$ ophthalmic solution instilled into the anterior chamber at the time of cataract surgery reported no statistically significant differences in corneal endothelial cell density after surgery or in corneal thickness after 1 month. ${ }^{10}$ It is inferred, based on the results of these studies, that high concentrations of MFLX in the corneal tissue would not cause any clinical adverse effects.

\section{Conclusion}

Although minor corneal SPK was observed in approximately $25 \%$ of cases, no adverse corneal effects appeared between the 2 antibiotics upon examination with instillation of LVFX and MFLX three times daily over 7 days.

\section{Acknowledgments}

We thank Yoko Saigo, Noriko Himori, Naoko Aizawa, Masayoshi Yukita, Ayumi Ota, Kazuko Omodaka, Ikumi Takatsu for helping the examination of the patients in this study and Nigel Fogden for editing this manuscript.

\section{Disclosure}

The authors report no conflicts of interest in this work.

\section{References}

1. Hussy P, Maass G, Tummler B, Grosse F, Schomburg U. Effect of 4-quinolones and novobiocin on calf thymus DNA polymerase alpha primase complex, topoisomerases I and II, and growth of mammalian lymphoblasts. Antimicrob Agents Chemother. 1986;29:1073-1078.

2. Bezwada P, Clark LA, Schneider S. Intrinsic cytotoxic effects of fluoroquinolones on human corneal keratocytes and endothelial cells. Curr Med Res Opin. 2008;24:419-424.

3. O'Brien TP, Arshinoff SA, Mah FS. Perspectives on antibiotics for postoperative endophthalmitis prophylaxis: potential role of moxifloxacin. J Cataract Refract Surg. 2007;33:1790-1800.

4. Robertson SM, Curtis MA, Schlech BA, et al. Ocular pharmacokinetics of moxifloxacin after topical treatment of animals and humans. Surv Ophthalmol. 2005;50 Suppl 1:S32-S45.

5. Miyata K, Amano S, Sawa M, Nishida T. A novel grading method for superficial punctate keratopathy magnitude and its correlation with corneal epithelial permeability. Arch Ophthalmol. 2003;121: $1537-1539$. 
6. Yokoi N, Takehisa Y, Kinoshita S. Correlation of tear lipid layer interference patterns with the diagnosis and severity of dry eye. $\mathrm{Am} J$ Ophthalmol. 1996;122:818-824.

7. Jalbert I, Stapleton F, Papas E, Sweeney DF, Coroneo M. In vivo confocal microscopy of the human cornea. Br J Ophthalmol. 2003; 87:225-236.

8. Ly LT, Cavanagh HD, Petroll WM. Confocal assessment of the effects of fourth-generation fluoroquinolones on the cornea. Eye Contact Lens. 2006;32:161-165.
9. Constantinou M, Daniell M, Snibson GR, Vu HT, Taylor HR. Clinical efficacy of moxifloxacin in the treatment of bacterial keratitis: a randomized clinical trial. Ophthalmology. 2007;114:1622-1629.

10. Espiritu CR, Caparas VL, Bolinao JG. Safety of prophylactic intracameral moxifloxacin $0.5 \%$ ophthalmic solution in cataract surgery patients. J Cataract Refract Surg. 2007;33:63-68.

\section{Publish your work in this journal}

Clinical Ophthalmology is an international, peer-reviewed journal covering all subspecialties within ophthalmology. Key topics include: Optometry; Visual science; Pharmacology and drug therapy in eye diseases; Basic Sciences; Primary and Secondary eye care; Patien Safety and Quality of Care Improvements. This journal is indexed on

Submit your manuscript here: http://www.dovepress.com/clinical-ophthalmology-journal

\section{Dovepress}

PubMed Central and CAS, and is the official journal of The Society of Clinical Ophthalmology (SCO). The manuscript management system is completely online and includes a very quick and fair peer-review system, which is all easy to use. Visit http://www.dovepress.com/ testimonials.php to read real quotes from published authors. 